\title{
Radar Observation of Rainfall System Modified by Orographic Effects
}

\author{
By Takao Takeda and Kunio Takase* \\ Water Research Institute, Nagoya University, Nagoya \\ (Manuscript received 22 February 1980, in revised form 12 August 1980)
}

\begin{abstract}
Modification of rainfall system by orographic effects was studied on the basis of the echo structure observed quantitatively by the use of a RHI radar which was set in Owase in the southeastern side of Kii peninsula during the period of June to July in 1977. Four cases of rainfalls were analyzed (cases A, B, C and D). In cases A, B and D continuous rain originated from middle-level clouds occurred over the broad area in Kii peninsula, and in case $\mathrm{C}$ convective rain was found out only in the limited area along the sea shore.

In case $C$ easterly wind was prevalent at low levels and a precipitating convective cloud system, which had the size of about $4 \mathrm{~km}$ in height and about $15 \mathrm{~km}$ in width of $\mathrm{E}$ to $\mathrm{W}$, was formed around the sea shore. It existed for more than two hours over the nearly same region. This long-lasting system was maintained as the group of small precipitating convective clouds which were formed successively in the same area over the sea and which travelled to the mountain side showing the same evolution. It can be inferred that the horizontal convergence caused by orographic effect in the windward side of mountains and by a downdraft in a previously developed cloud would have played an important role in the successive formation of new convective clouds.

In case $A$ easterly wind was prevalent in the lower layer and a low-level cloud system which seemed to be the same type as case $\mathrm{C}$ was formed around the sea shore below middlelevel precipitating clouds. Precipitation originated from middle-level clouds increased remarkably in low-level clouds. However, in case B in which westerly wind was prevalent in the lower layer, a low-level cloud system was not detected and precipitation from middlelevel clouds was not observed to increase at low-levels. In case D the "seeding effect" of precipitation particles of middle-level clouds on low-level clouds was suggested.
\end{abstract}

\section{Introduction}

It is well established that the horizontal distribution of rainfall is closely associated with topography and heavy rain often occurs in the mountainous region. Though it will be doubtless that rainfall systems are modified by orographic effects, the process of modification is much complicated and it will be different for an individual case of rainfall.

Since the formation of orographic rain or the orographic enhancement of rainfall is much dependent upon the direction of prevailing wind at low levels, many authors tried to estimate the rainfall produced by an upcurrent forced by orography (e.g. Sawyer, 1956: Sarker, 1966). In

\footnotetext{
* Present affiliation: Niigata Meteorological Observatory.
}

most of these models condensed water in the upcurrent was assumed to precipitate instantaneously. Recently Colton (1976) simulated the orographic rain by a fine-mesh mesoscale model, and Gocho (1978) presented a numerical experiment of orographic rain caused by stratiform clouds, taking into account microphysical processes related to the growth and evaporation of drops.

In the meantime it has been pointed out by some authors that the orographic enhancement of rainfall is associated with the interaction between different types of rain. Staff Members of Tokyo Univ. $(1969,1970)$ stated in the study of typhoon rainfall that the interaction between orographic rain and convective rain of typhoon rainbands was important for the enhancement of rainfall in the mountain range. Sakakibara and Takeda (1973) also suggested in the analysis of 
typhoon rainfall that the orographic amplification of rainfall would be a result of the addition of many small water drops existing in low-level clouds to raindrops falling from convective clouds of high top and the capture of the former drops by the latter drops. Further Takeda et al. (1976) made a detailed case study of heavy rain and they inferred that travelling cumulonimbi produced heavy rain in a limited area on account of their interaction with surrounding precipitating clouds of low top which would have been formed by orographic influence. Browning et al. (1974) pointed out in the case study of rainfall around the South Wales hills that precipitation was gencrated by orographic ascent at middle-levels far upwind of the hills and some of the precipitation seeded low-level clouds over the hills. In order to predict the orographic enhancement of rainfall in the mountain range quantitatively, Tatehira (1976) developed a numerical model, taking into account the growth of raindrops originated from meso-scale disturbance in low-level clouds.

Now it is to be paid attention to that orographic rain might be of a layer-cloud type in some cases and of a convective type in other cases and that there might be various types of interaction between cloud systems in the orographic enhancement of rainfall. The modification process of rainfall system by orographic effect will be much different between the system composed of convective clouds and the system of middle-level layer clouds, in other words between "shower" and "continuous rain".

In order to increase the physical understanding of the formation of orographic rain and the orographic enhancement of rainfall, the threedimensional structure of rainfall systems which are actually influenced by orography should be observed in detail. It is well known that over Kii peninsula in Japan we often have larger amount of rainfall in the area around Owase City than in surrounding areas and heavy rain also occurs there frequently, specially in the situation in which an easterly is prevalent at lowlevels. Yanagisawa et al. (1974) showed from radar observation of typhoon rainfall in Owase that many echoes of tops lower than $3 \mathrm{~km}$ were distributed densely around Owase and Fujiwara et al. (1974) suggested in the analyses of showers formed in Owase area that the structure of rain system composed of tower clouds and low-level clouds was important in the development of heavy rain.

During the period of June to July in 1977 we made observations of several types of rainfall system mainly by a RHI radar of Nagoya Univ. set at Owase. The purpose of this paper is to clarify the structure of rainfall systems which were formed or modified by orographic effects on the. basis of quantitative observations by the RHI radar. Specially the fine structure of low-level precipitating cloud system formed around Owase, whose interaction with other types of cloud system has been stated to be important in the enhancement of rainfall, and the modification of rainfall system related to middle-level layer clouds (a)

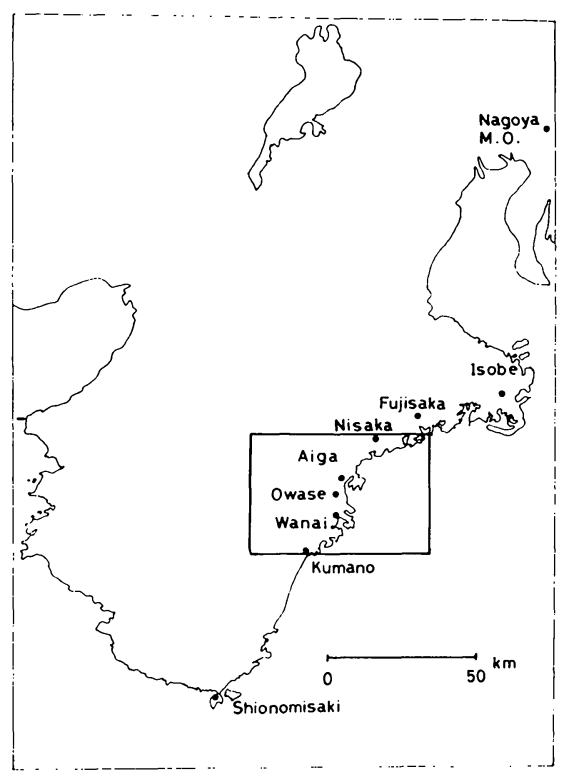

(b)

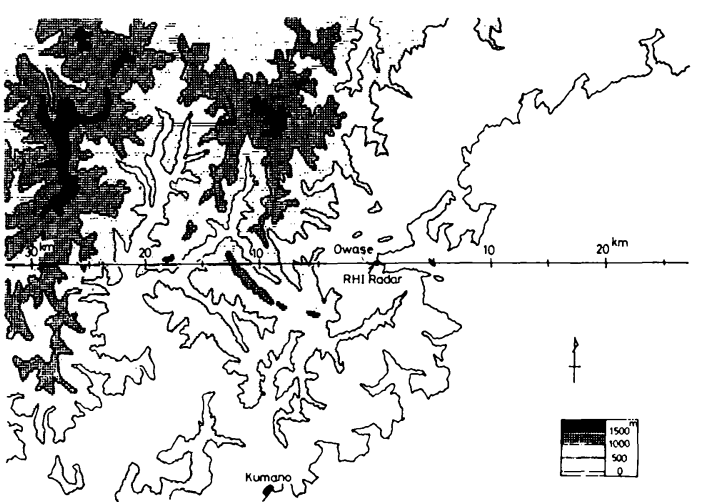

Fig. 1 (a) Kii peninsula and stations of meteorological observations. (b) Topography in the framed area of Fig. (a) and the location of the vertical plane in which the beam of the RHI radar was scanned. 
by orographic effect will be described in detail.

\section{Brief description of radar observation and rainfalls}

\section{1) Outline of RHI radar observations}

A RHI radar of Nagoya University was set in Owase city, which is shown in Fig. 1a, in Kii peninsula during the period of June to July in 1977 and the echo structure of rainfall systems which would have been subject to orographic effects was observed. As seen in Fig. 1b, it is a characteristic feature in the topography around Owase city that mountains higher than $500 \mathrm{~m}$ are very close to the seashore line running in the direction of NE to SW. The beam of the radar was scanned mainly in the vertical plane of $E$ to $\mathrm{W}$, since it was desirable to observe the change in the structure of precipitating clouds formed in the situation of easterly wind and since it was not so easy to observe in the vertical plane of $\mathrm{N}$ to $\mathrm{S}$ because the shadow area caused by nearby hills was large in the vertical plane.

The radar is $3.2 \mathrm{~cm}$ in wave length, $40 \mathrm{kw}$ in peak transmitting power, $1 \mu \mathrm{s}$ in pulse length, $750 \mathrm{c} / \mathrm{s}$ in pulse repetition frequency and $6 \mathrm{rpm}$ in rotation speed of an antenna. It was connected with a data processor and we obtained equivalent radar reflectivity factors $\left(Z_{e}\right)$ at 2430 grid points in the vertical plane about every $1 \mathrm{~min}$. The value of $Z_{e}$ at each grid point is given by averaging the data of 25 pulses. Arranged grid points are shown in Fig. 2. Though the intervals of grids are variable, $\Delta X$ and $\Delta Z$ were taken to be $500 \mathrm{~m}$ and $250 \mathrm{~m}$, respectively and so the size of the domain in which quantitative observations

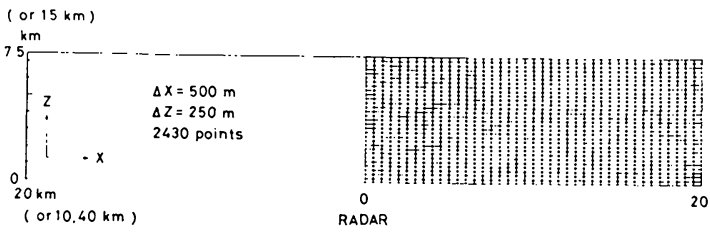

Fig. 2 Grid points at which equivalent radar reflectivity factors are given quantitatively by a data processor.

were made is $40 \mathrm{~km}$ horizontally and $7.5 \mathrm{~km}$ vertically. The analyses in this paper were made on the basis of the vertical cross sections of equivalent radar reflectivity factor. The influence of attenuation caused by raindrops existing on the way is not taken into account.

2) Four cases of rainfalls

Several types of rainfalls were observed in

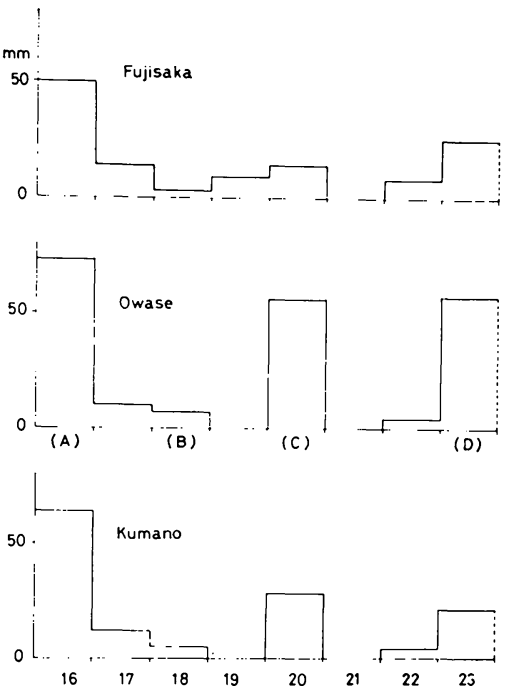

Fig. 324 hours rainfall amounts at Fujisaka, Owase and Kumano during the period of the 16 th to the 23 rd of June. Rainfalls named A, B, C and D werc analysed.

June. Fig. 3 shows 24 hours rainfall amounts during the period of the 16 th to the 23 rd in June at three stations located along the sea-shore line. The period was in the early stage of "Baiu" and a Baiu front was located far southward from Kii peninsula as seen in Fig. 4. Rainfalls observed on the 16th, 18th, 20th and 23rd were analysed. They will be named cases A, B, C and D for convenience' sake, respectively, hereafter - A: 15.30 to $24.00 \mathrm{LST}$ on the $16 \mathrm{th}, \mathrm{B}: 2.00$ to 7.00 LST on the 18th, C: 0.00 to 5.00 LST on the 20th and D: 0.00 to 10.00 LST on the 23rd.

In all of three cases excepting case $\mathrm{C}$ continuous rain occurred over the broad area in $\mathrm{Kii}$ peninsula and bright bands were recognized in vertical cross section of radar echo observed around Owase. In case $\mathrm{C}$, as described later, convective rain was found out only in the limited area located along the sea-shore line. On the basis of the structure of radar echo the influence of orography on a convective rainfall system will be discussed in the first half of the present paper and the influence on rainfall systems which are originated mainly from middle-level precipitating clouds will be described in the latter half.

\section{Convective rain observed in the limited area along the sea-shore line (case $\mathrm{C}$ )}

\section{1) Outline of rainfall}

During the period of 21.00 of the 19th to 6.00 

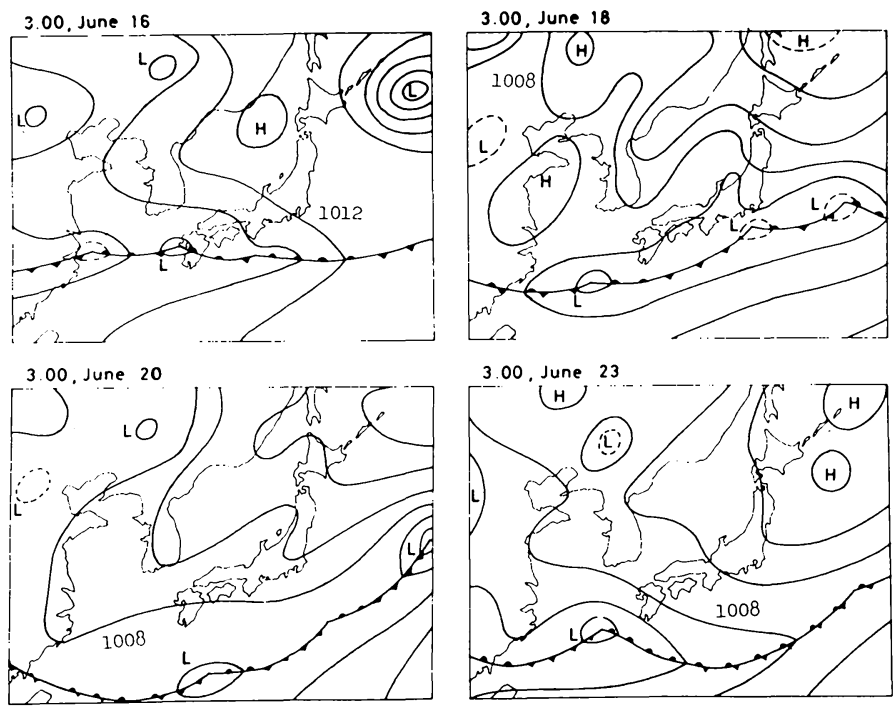

Fig. 4 Weather maps on the 16th, 18th, 20th and 23 rd of June. Isobars are drawn every $4 \mathrm{mb}$.

of the 20th it rained in the limited area in Kii Peninsula (Fig. 5). The rain was judged mainly by RHI-radar observation to be a convective type. Rainfall more than $20 \mathrm{~mm}$ was seen only in the small area which is located along the sea-shore line and on the southeastern side of mountains. It is to be noted that the area of rainfall was

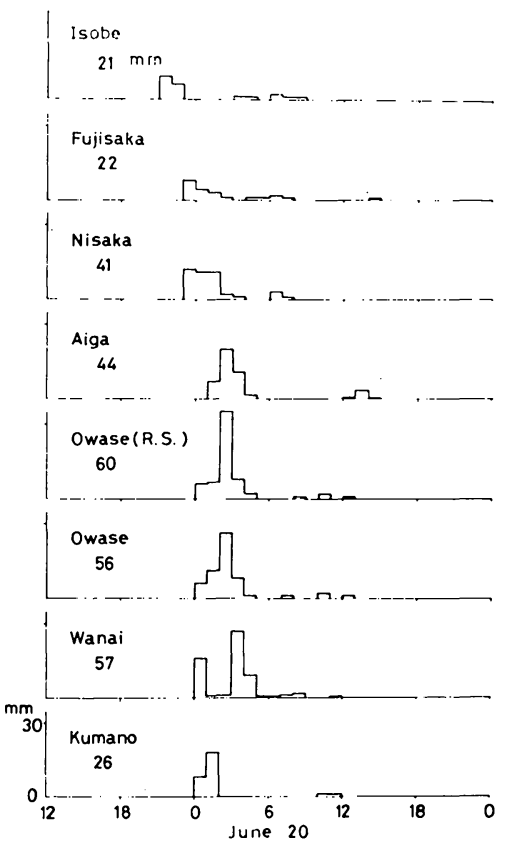

Fig. 5 Hourly rainfall and total rainfall at stations which are shown in Fig. 1a. Owase (R.S.) is the radar site in Owase. limited in the area which is within $20 \mathrm{~km}$ from the sea-shore line. Rainfall amount was larger specially in the area around Owase than in the surrounding area.

During the period of the 19th to the 20th, as seen in Fig. 4, a Baiu front was more than 1,000 $\mathrm{km}$ southward from Owase. Upper air soundings at Shionomisaki station shown in Fig. 6 indicate that easterly winds were prevalent at the levels below $800 \mathrm{mb}$.

Fig. 7 is the time variation of echo patterns observed by a PPI radar of Nagoya Meteorological Observatory (Fig. 1a) which is $140 \mathrm{~km}$ northeastward from Owase. Before 0.00 of the 20 th we could hardly detect any radar echoes other than a band-like cluster of convective echoes. After having been formed over the sea they travelled to the land with the speed of about $10 \mathrm{~km} /$ hour. It can be seen in Fig. 7 that convective echoes were intensified in landing the sca-

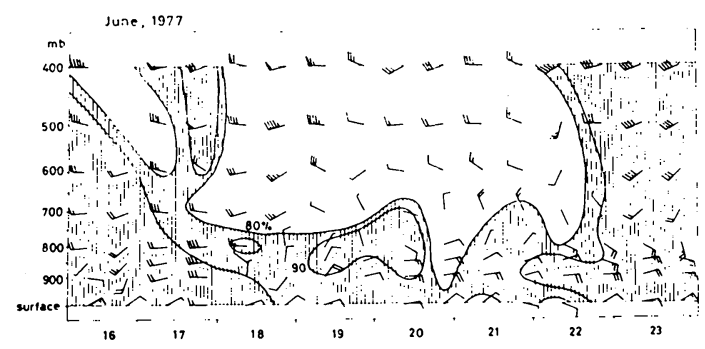

Fig. 6 Winds and relative humidity above Shionomisaki station. Relative humidity is more than $80 \%$ in shaded area. 


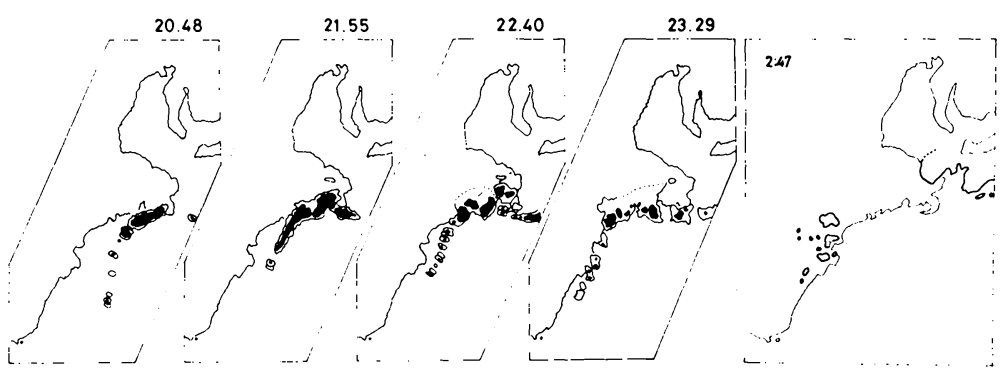

Fig. 7 Echo patterns of levels 4 and 6 observed by PPI radar of Nagoya Meteorological Observatory, which correspond to 16 and $64 \mathrm{~mm} /$ $\mathrm{hr}$ in rainfall intensity roughly, respectively.

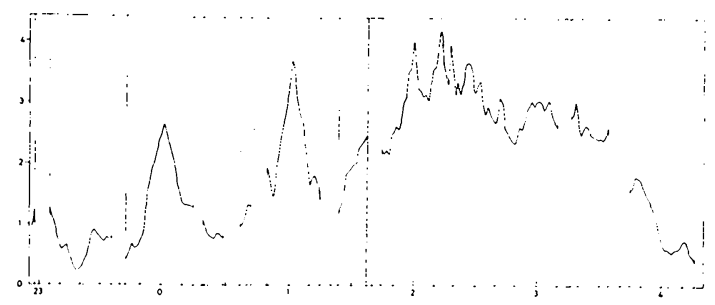

Fig. 8 Time variation of total rainwater in the plate-like atmosphere of unit thickness, 7.5 $\mathrm{km}$ in height and $40 \mathrm{~km}$ in width of $E$ to $W$. Ordinate is represented in arbitrary unit.

shore and they were considerably modified in their configuration. The echo pattern at 2.47 shows that echoes vanished after having landed, excluding the area around Owase. However, it might be possible that PPI radar of Nagoya Meteorological Observatory did not detect echoes whose top was below the level of $1 \mathrm{~km}$, because of the influence of the elevation angle of radar beam and of the mountains existing on the way. Unfortunately the observation by PPI radar was not performed during the period of 23.30 to 2.30 and we could not know echo patterns during the period.

Structures of the travelling band-like echo cluster were observed in the vertical plane of $\mathrm{E}$ to $\mathrm{W}$ by $\mathrm{RHI}$ radar in Owase about every one minute. At about 23.00 band-like radar echoes arrived at the point of $15 \mathrm{~km}$ eastward from the radar site and then their structure were observed quantitatively until 4.00 on the 20th. No other ccho was found out in the vertical plane of $E$ to $\mathrm{W}$, even beyond $20 \mathrm{~km}$ from radar site.

Fig. 8 is the time variation of total rainwater amount in the plate-like atmosphere of unit thickness which has the size of $7.5 \mathrm{~km}$ in height and $40 \mathrm{~km}$ in the direction of $\mathrm{E}$ to $\mathrm{W}$. Rainwater amount was converted from radar reflectivity

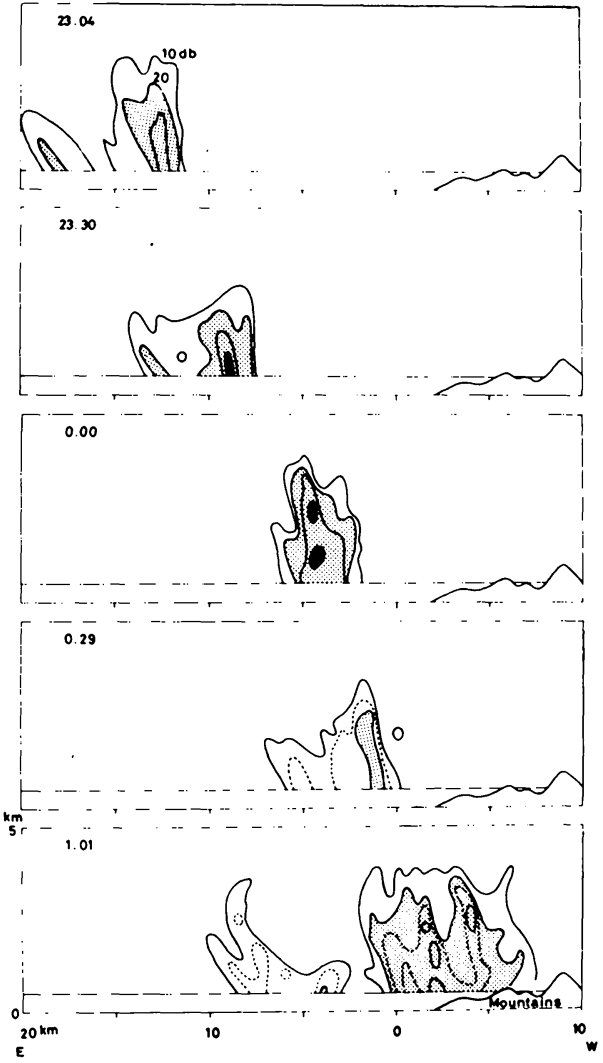

Fig. 9 Vertical cross sections of "echo intensity" $10 \log Z_{e}\left(Z_{e}\right.$ is equivalent radar reflectivity factor). Contours are drawn every $10 \mathrm{db}$ and dotted lines are contours of $15 \mathrm{db}$ or $25 \mathrm{db}$. Echo intensity is larger than $40 \mathrm{db}$ in black area.

factor at each grid point, using a relationship which was obtained on the basis of the size distributions of raindrops at radar site and radar reflectivity factor over the site. Its absolute value is not so reliable and only its time variation will be discussed here. The ordinate of the figure is 
expressed in arbitrary unit. It is to be paid attention to that there are three peaks of total rainwater during the period. The structure of echo will be described together with the time variation of total rainwater in following sections.

\section{2) Change in echo structure before landing}

Equivalent radar reflectivity factor $Z_{e}$ is expressed in the value of $10 \log Z_{e}$ in most of figures of the present paper. $10 \log Z_{e}$ will be called "ccho intensity" hereafter for convenience' sake. Vertical cross sections of echo intensity of a travelling echo system are shown in Fig. 9. It is interesting that the echo system have a tendency to be long-lasting so far as its behavior is treated in the vertical plane of $\mathrm{E}$ to $\mathrm{W}$, though it showed some changes in the structure. It retained the size of $5 \mathrm{~km}$ in width and 2.5 to $3.5 \mathrm{~km}$ in height until 0.29 . The first peak value shown at about 0.00 in Fig. 8 was seen when the travelling echo system became most intensive immediately before its landing. The second peak value appearing at 1.00 was seen in the stage of modification of the system occurring after landing. These two peak values would correspond to the intensification of convective echoes and the modification of their configuration which appeared in landing the sea-shore in PPI echo patterns of Fig. 7.

We can find out an interesting fact in the structure of the travelling echo system obtained cvery one minute. Though the echo system

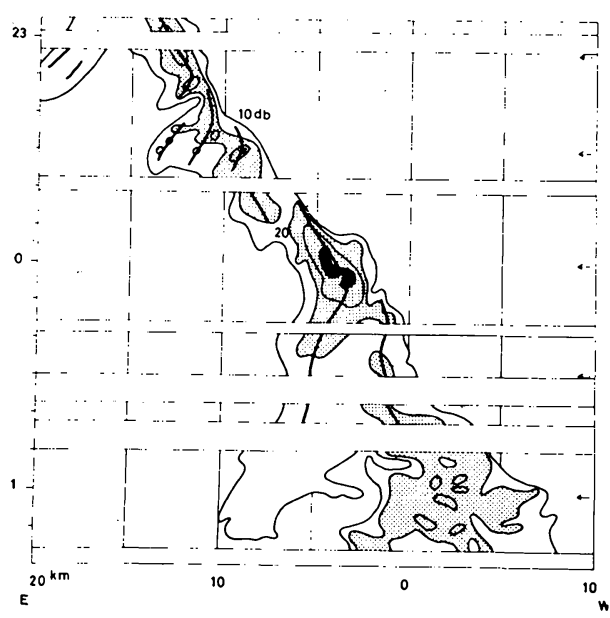

Fig. 10 Movement of echoes in the direction of $E$ to $\mathrm{W}$ at the level of $1 \mathrm{~km}$. Contours are same as in Fig. 9. Thick solid lines indicate the location of the center of echo units. Arrows are the time at which cross sections are shown in Fig. 9. seemed to be long-lasting, the convective echoes composing the system were replaced by newly developed echoes which appeared in the front side of the travelling system. The old echo alters its movement to scparate from the new echo which travels westward (to the sea-shore). Echoes seen in the eastern part of the echo system in Fig. 9, excepting the echo at 0.00 , are ones separating from the system.

Their behavior can be seen more clearly in Fig. 10 which shows the movement of echoes in the direction of $\mathrm{E}$ to $\mathrm{W}$ at the level of $1 \mathrm{~km}$. Echo intensity in the figure is a running average in the area of $2.5 \mathrm{~km}$ in width of $\mathrm{E}$ to $\mathrm{W}$. Though the echo system is long-lasting as a whole, the constituent of the system is replaced by new echoes several times. Thick lines indicate the center of individual convective echo unit at the level of $1 \mathrm{~km}$. New echoes appeared at the western edge of the echo system, that is, in its frontal side. Each center begins to move eastward after the appearance of the new echo. The old echo can be interpreted to be carried away by westerly winds seen above $800 \mathrm{mb}$ level. After the most intensive echo among those which appeared successively in the echo system began to move eastward dissipating at about 0.30 , the echo existing in the western part of the system loses the clear structure of a convective echo and its width becomes wider as shown in the lowest part of Fig. 9.

It is to be noted that total rainwater in the vertical plane reached the second peak value at this stage. The system of travelling precipitating convective clouds can be said to have shown two types of efficient production of rainwater in landing-one is the efficient production of large raindrops in the small region within the cloud as inferred from the appearance of the intensive echo, and another is the efficient conversion of condensed water into raindrops in the broad region. Echoes which are shown at 0.00 and at 1.01 in Fig. 9 correspond to these two types, respectively.

3) Fine structure of a long-lasting echo system formed around Owase

i) Behaviors of echo units

After the echo system shown in the lowest part of Fig. 9 dissipated both in its size and in its intensity, a new echo system was formed around Owase at about 1.30. As inferred from the time variation of total rainwater shown in Fig. 8, the echo system existed for more than two hours. 
The size and location of the system did not show a remarkable change as a whole. Fig. 11 is the structure of the system which was made by averaging echo intensity at each grid point during the period of 1.44 to 3.07 . The size of the system with intensity more than $10 \mathrm{db}$ was $15 \mathrm{~km}$ in width of $\mathrm{E}$ to $\mathrm{W}$. The rainfall amount associated with the long-lasting echo system occupied almost $80 \%$ of the total rainfall amount recorded from 0.00 to 6.00 both at Owase meteorological station and our radar site.

Fig. 12 is the time change of the vertical cross

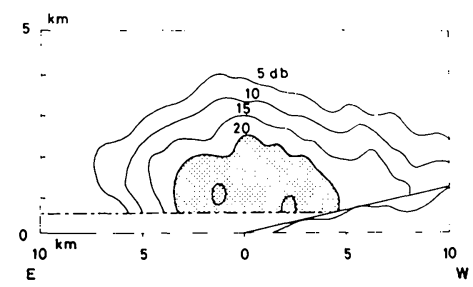

Fig. 11 Structure of the echo system averaged during the period of 1.44 to 3.07 .
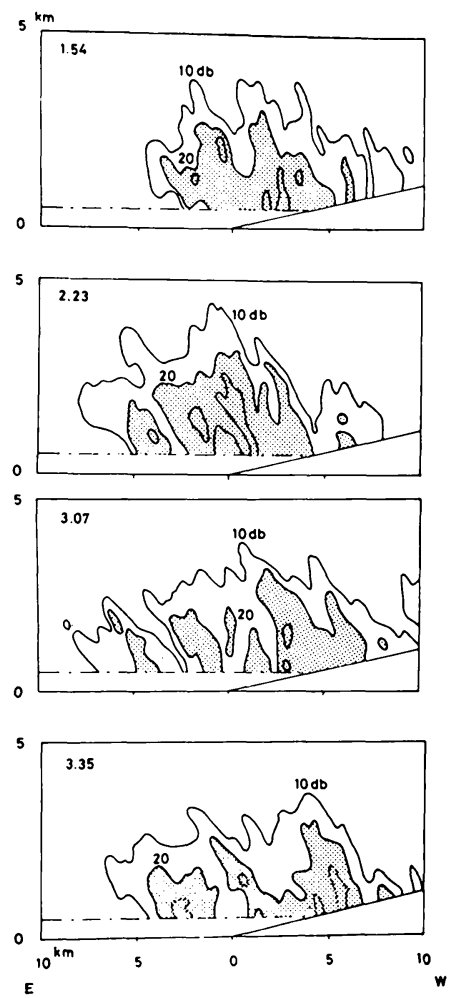

Fig. 12 Vertical cross sections of echo intensity. Contours are same as in Fig. 9. Triangular area in the right side shows the shadow of radar caused by nearby hills.

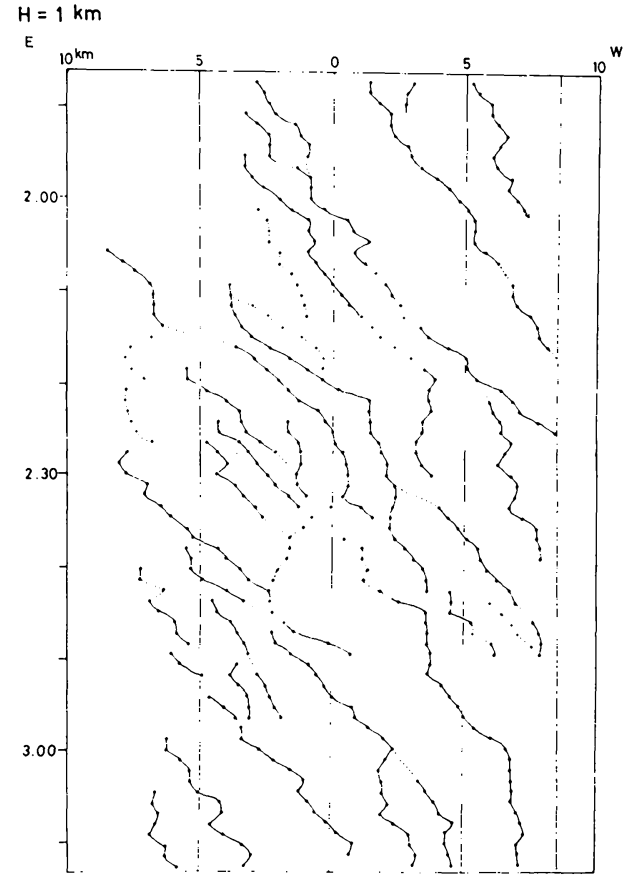

Fig. 13 Movements of echo units at the level of $1 \mathrm{~km}$. Dotted lines mean that echo units were not defined clearly.

section of echo intensity. The size of the system defined by $10 \mathrm{db}$ is about $4 \mathrm{~km}$ in height and about $15 \mathrm{~km}$ in width. We did not detect any echo above the level of $0^{\circ} \mathrm{C}$, which was observed to be about $4,300 \mathrm{~m}$ at 21.00 on the 19 th by upper air sounding at Shionomisaki station. It will be reasonable to say that the echo system was related to precipitating convective clouds of a warm-rain type.

It is to be noted that the echo system is persistently composed of several small echo units in vertical cross sections of Fig. 12. These echo units are arranged with the interval of 3 to $4 \mathrm{~km}$. The westward component of their movement is clarified by more detailed analyses based on vertical cross sections obtained every one minute. Fig. 13 summarizes their movements at the level of $1 \mathrm{~km}$. In tracing the center of individual echo unit in the vertical plane of $\mathrm{E}$ to $\mathrm{W}$, the center was identified on the basis of vertical cross sections and of the spacial variation of echo intensity averaged vertically. Naturally only a few echo units continued to be traced in the plane for a long time on account of the $\mathrm{N}$ to $\mathrm{S}$ component of echo movements though the main direction of movements was westward. We were able to trace the unit for $50 \mathrm{~min}$ at longest $(30 \mathrm{~min}$ on an 


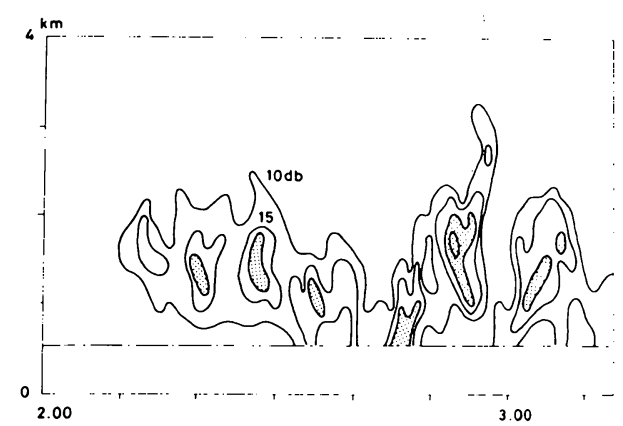

Fig. 14 Time-height cross sections of echo intensity above the point of $6 \mathrm{~km}$ out at sca. Contours are drawn every $5 \mathrm{db}$.

average). Fig. 13 indicates that several echo units were always found out in the vertical plane and their speeds were 15 to $25 \mathrm{~km} /$ hour at the level of $1 \mathrm{~km}$. It is interesting that new echo units detected on the most eastern side appeared in the nearly same area-3 to $8 \mathrm{~km}$ to the sea side of radar site-and that they were formed with the time interval of a few to ten-odd minutes (about 10 minutes on an average).

Figs. 14 and $15 \mathrm{a}$ are time-height cross sections of echo intensity made at $6 \mathrm{~km}$ eastward and at $1 \mathrm{~km}$ westward from the radar site. The former point is near the area where new echo units began to be detected and the latter is near Owase meteorological station. Fig. 14 indicated that intensive echoes appeared with the interval of about ten minutes and most of echoes of intensity more than $15 \mathrm{db}$ existed aloft without extending $500 \mathrm{~m}$ level. Though echo units passed periodically above the point of $6 \mathrm{~km}$ on the sea side, most of raindrops would have been retained in clouds without reaching the earth surface.

The periodical passage of echo units is also seen clearly above Owase station as seen in Figs. $15 \mathrm{a}$ and $15 \mathrm{~b}$. Fig. $15 \mathrm{~b}$ is the time change of vertically integrated amount of rainwater which was converted from radar reflectivity factor in a similar way to Fig. 8. It is interesting that the passage of echo units seems to be reflected by the change in the velocity and direction of winds measured on the ground, which are shown in Figs. $15 \mathrm{c}$ and $15 \mathrm{~d}$. The peak values of wind velocity are often found out nearly at the same time as those of integrated rainwater. The downdraft caused in association with many falling raindrops is suggested to have reached the earth surface around Owase station. Thus the longlasting echo system can be concluded to have

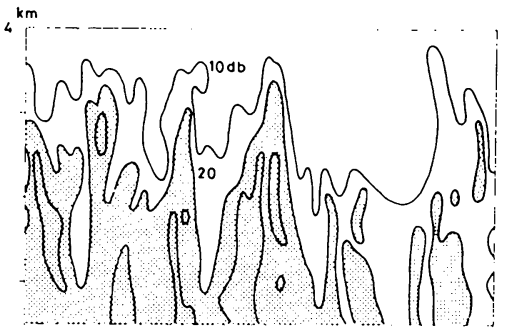

(a) $0 !$

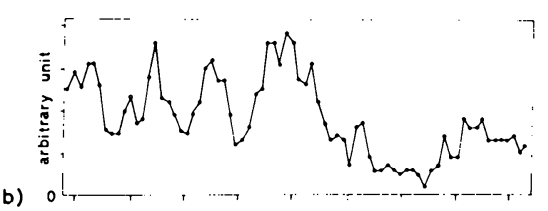

(c)

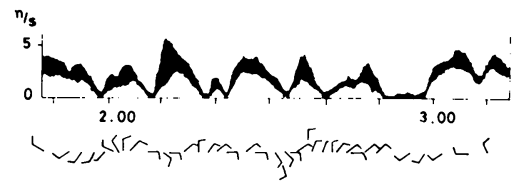

Fig. 15 (a) Time-height cross section of echo intensity above Owase station. Contours are drawn every $10 \mathrm{db}$. (b) Time variation of vertically integrated rainwater above Owase station. Ordinate is in arbitrary unit. (c) and (d) Speed and direction of winds at Owase station. The range of fluctuation in the speed is represented by black areas.

bcen composed of travelling echo units which were arranged with the interval of a few $\mathrm{km}$ in the direction of $\mathrm{E}$ to $\mathrm{W}$.

Fig. 16 is the change in the intensity of an individual echo unit with its travelling at the level of $1 \mathrm{~km}$. Though we were not able to trace echo units completely in the vertical plane of $\mathrm{E}$ to $\mathrm{W}$ because of $\mathrm{N}$ to $\mathrm{S}$ component of their movements, it can be said that they have a tendency to reach the largest intensity around radar station, that is, near the sea-shore in travelling from the sea to the mountains. Their intensity seems to have decreased rather gradually after they passed over the sea-shore while it increased rapidly before reaching the sea-shore.

In vertical cross sections obtained every $1 \mathrm{~min}$ the individual echo unit is seen to have inclined with time in the direction of $\mathrm{W}$ to $\mathrm{E}$. The inclination of echo units will be made clear by Fig. 17 which indicates the movements of their centers at the level of $3 \mathrm{~km}$. They show much different movements from those at the level of $1 \mathrm{~km}$ and a large part of them tend to move eastward (from the mountains to the sea). Most of echo units 


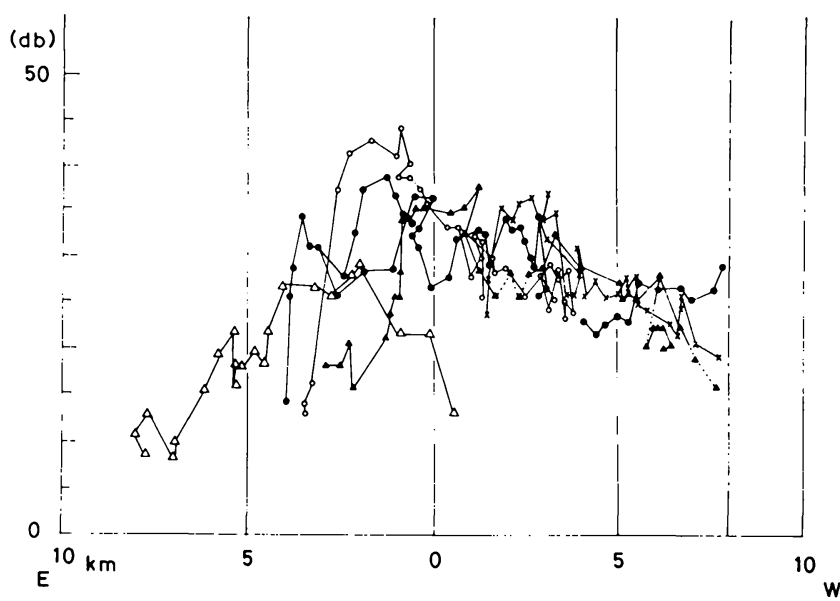

Fig. 16 Change in the echo intensity of individual echo units with their travelling.

appeared at the level of $3 \mathrm{~km}$ in the region between $3 \mathrm{~km}$ to the sea-side and $5 \mathrm{~km}$ to the mountain-side where travelling echo units became most intensive at the level of $1 \mathrm{~km}$.

Fig. 18 shows that winds changed from an easterly to a westerly around the level of $700 \mathrm{mb}$ (that is, about $3 \mathrm{~km}$ ) in the vertical plane of $\mathrm{E}$ to $\mathrm{W}$. The above-mentioned features of the echo system and echo units are summarized as follows on the basis of the vertical profile of prevailing winds. The echo system which remained almost stationary for two hours had the size of $4 \mathrm{~km}$ in height and $15 \mathrm{~km}$ in width of $\mathrm{E}$ to $\mathrm{W}$ and it was composed of several echo units of 3 to $5 \mathrm{~km}$ in width. They appeared with the interval of about $10 \mathrm{~min}$ on the eastern edge of the echo system which was around $5 \mathrm{~km}$ out at sea. They travelled westward (to the mountain-side) with the speed of 15 to $20 \mathrm{~km} /$ hour. Their intensity and the height of their top reached the peak value around the sea-shore and they became inclined eastward (in the direction of vertical shear) gradually with extending upward.

ii) Discussion on the structure of the long-lasting cloud system

These facts mean that the long-lasting precipitating cloud system which was fixed around the sea-shore in front of the mountains was maintained as the group of small convective clouds which formed almost in the same area over the sea and which travelled to the mountains. Upperair sounding at Shionomisaki station indicates that the atmosphere was conditionally unstable at low levels. It is to be noted that the cloud system was not a layer type expected from an

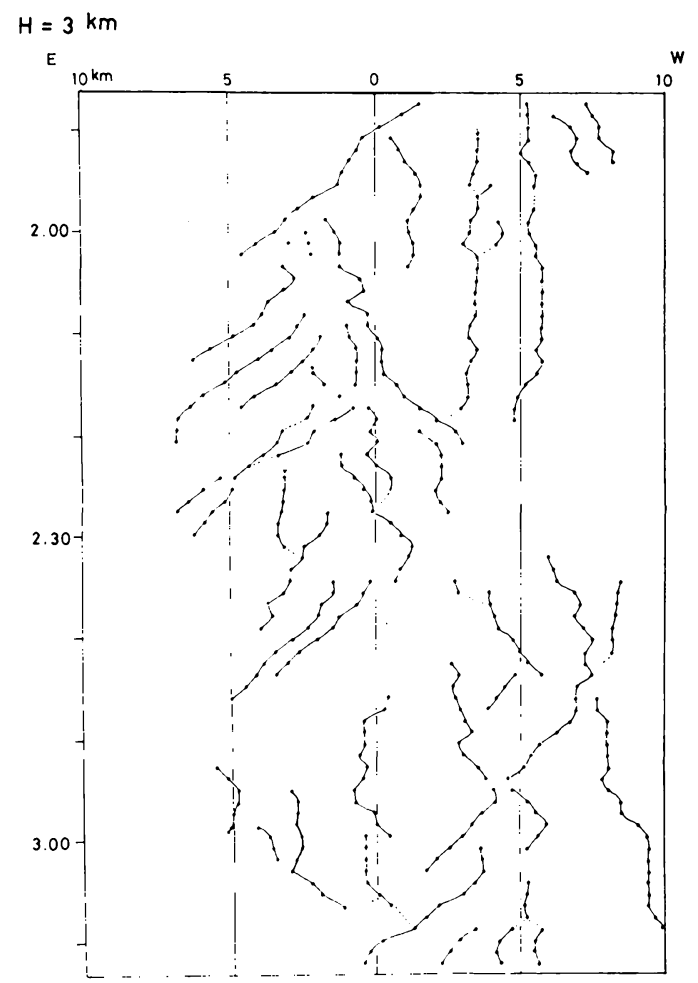

Fig. 17 Movements of echo units at the level of $3 \mathrm{~km}$.

upcurrent forced due to orographic effect, but a convective one, and the top of individual convective clouds exceeded the level of $4 \mathrm{~km}$ though the height of the mountains is about $1 \mathrm{~km}$.

Though neither clouds nor updrafts (also downdrafts) could be detected by the radar, the long- 


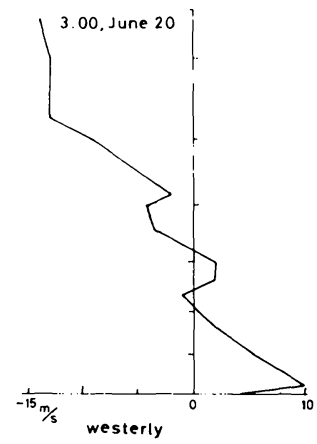

Fig. 18 Vertical profiles of $\mathrm{E}$ to $\mathrm{W}$ wind component. Easterlies are represented as positive values in the abscissa.

lasting precipitating cloud system can be inferred to have the structure such as shown schematically in Fig. 19a. Convective clouds associated with echo units will be of a so-called short-lived type, since individual echo unit became inclined to the downshear side and its life was about a few ten minutes. As well established in two-dimensional numerical model (ex. Takeda, 1971) the updraft and the downdraft would have been arranged in the upshear side and in the downshear side, respectively in short-lived convective cloud, while the updraft would have the feature of upshear tilting and the downdraft would be formed in its upshear side in a long-lasting one. They would have changed with travelling from the left to the right in such a way as shown in the figure. That is, convective upcurrents are tilted to the downshear side and raindrops produced in it fall in its downshear side. Consequently the downdraft is also caused in the downshear side of the upcurrent. As described above, a new convective upcurrent was formed almost in the same area over the sea and it travelled to the mountains in the direction of winds at low levels. We can conclude that though individual convective clouds were not long-lasting, the cloud composed of them showed the feature of long-lasting system because they were formed successively in the same area and they travelled in the same direction showing the same evolution.

If the hypothetical vertical velocity of air was averaged at each point of the cloud system with the structure shown in Fig. 19a in a similar way to the averaged echo system of Fig. 11, resultant averaged upcurrent and downcurrent would have been arranged in such a way as shown in Fig. 19b. This arrangement might be very favourable for the maintenance of the system, since it has

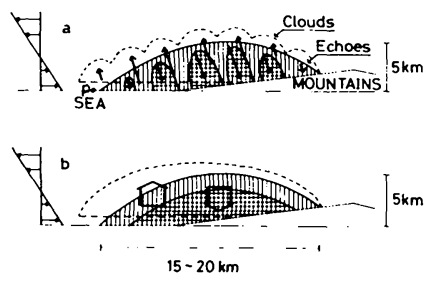

Fig. 19 Schematic representations of the structure of the long-lasting precipitating cloud system (a) and its averaged structure (b).

the same structure as an organized long-lasting convective system-the averaged downcurrent as well as main part of precipitation is located in the upshear side of the averaged upcurrent.

Now there are two problems to be solved. One is why new convective clouds were formed almost in the same area over the sea. Another is whether or not the precipitating cloud system was maintained to be long-lasting partly as a result of a large organized structure such as shown in Fig. $19 \mathrm{~b}$, though it can be interpreted to be longlasting as a group of convective clouds which showed the above-mentioned behaviors. How orographic effects were related to these two problems will be also to be solved.

Now we have no observational data for discussing these problems. It will be highly probable, though it could not be verified, that a strong horizontal convergence was caused at low levels around $\mathrm{P}$ point in Fig. 19a by two processes which are related to the influence of orography on the prevailing easterly and a cold current diverging from the downdraft in previously developed clouds, respectively. The latter process can be inferred to have occurred intensively to the eastern side of an existing downdraft in the situation of vertical shear shown in Fig. 19. The intermittent formation of new convective clouds with the interval of about $10 \mathrm{~min}$ seems to suggest the importance of the downdraft, since it will take over $10 \mathrm{~min}$ for a downdraft to be formed in the new cloud. Judging from Figs. 15c and $15 \mathrm{~d}$ it is reasonable to say the existence of the downdraft in precipitating clouds. The effectiveness of two processes on the formation of the long-lasting precipitating cloud system such as described here will be much dependent upon the degree of conditional instability in the lower atmosphere. The existence of mesoscale convergence which would cause the system to be a large organized system could not be verified at present. 
As seen in Fig. 8, total rainwater amount remained high for two hours. Since it is not expected that the amount of transported water vapor and the condition of thermal instability changed so much during the period of 23.00 to 4.00 , the production of rainfall can be said to have been much more efficient after 1.30 than before 1.30 as a result of the formation of the long-lasting cloud system which was fixed around the sea shore.

It is interesting that new echo units appeared on a quite opposite side of the system in the travelling long-lasting convective cloud system described in previous section and the fixed longlasting cloud system described in this section. It will be also problems to be solved in future why the former system dissipated in its landing and whether or not it had a role of a trigger in causing the formation of the latter system.

\section{Modification of rainfall originated from middle-level clouds}

As described briefly before, bright bands were observed by the RHI radar for rainfalls on the 16th, 18th and 23rd. The rainfall can be said to have been originated, at least partly, from middle-level clouds on these days. The time variation of hourly rainfall at Owase station is shown in Fig. 20 together with 24 hours rainfall at Fujisaka and Kumano the location of which are indicated in the map of Fig. 1a. As seen in

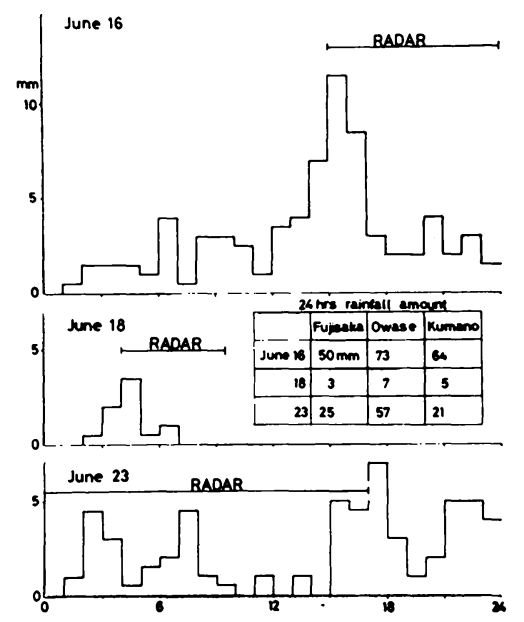

Fig. 20 Time variation of hourly rainfall at Owase on the 16th, 18th and 23rd of June. 24 hours rainfalls are also shown together with those at Fujisaka and Kumano. Bars indicate the period of RHI radar observations.
Fig. 4 a Baiu front lay very far from Kii peninsula in all of three days, and middle-level clouds produced continuous rain in a wide area. It is interesting that 24 hours rainfall amount at Owase was larger than those at other two stations in these cases, though the difference seen on the 18 th would not be significant. The period of RHI radar obscrvations is also shown in Fig. 20. Modification of rainfall originated from middlelevel clouds will be discussed below on the basis of the structure of radar echoes.

\section{1) Rainfall on the 16th of June}

i) Modification by low-level clouds

Bright bands were found out continuously over Owase during RHI radar observations on the 16th. Fig. 21 is the patterns of PPI radar echoes obtained at Nagoya Meteorological Observatory. Echoes existed over a wide area of Kii peninsula. It is to be noted that intensive echoes of level 4 were seen to be unevenly distributed and to be concentrated specially around Owase during the period of 15.0 ' to 17.00 . It rained heavily at Owase station during the period. Though no echo of level 4 could be detected at 17.00 over Kii peninsula, we can still see the tendency that intensive echoes were more frequently observed around Owase than in other areas. We could not find out the tendency after 21.00 .

RHI radar observation carried out from 15.00 to 24.00 shows that the fine structure of echoes observed before 20.00 was much different from those after 21.00. Figs. $22 \mathrm{a}$ and $22 \mathrm{~b}$ are the

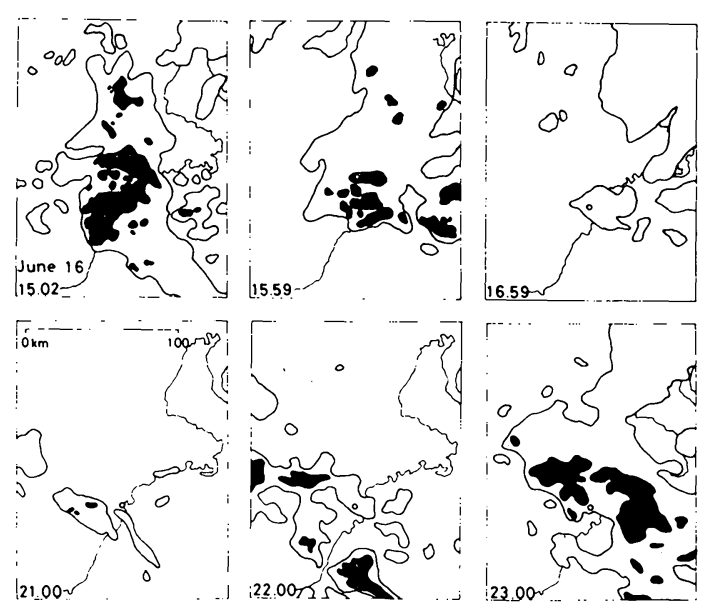

Fig. 21 Echo patterns of levels 2 and 4 observed by PPI radar of Nagoya Meteorological Observatory. Small open circles indicate the place of Owase. 
typical examples of vertical cross sections of echo intensity obtained before 20.00 and after 21.00 , respectively. Bright bands appeared around the level of $4.25 \mathrm{~km}$. It is to be noted in Fig. $22 \mathrm{a}$ that an intensive echo of $20 \mathrm{~km}$ in width of E to W was found out at low levels around Owase and that echo intensity increases with decreasing height below the bright band. This fact implies that precipitating clouds were formed at low levels around Owase besides middle-level clouds. The top of low-level clouds will be inferred from the echo structure to exceed at least $3 \mathrm{~km}$. It would be reasonable to say that this cloud system was of the same type as described in the previous chapter. As seen in Fig. $22 \mathrm{~b}$, the remarkable increase of echo intensity with decreasing height could not be seen after 21.00 below the bright band, though we can detect more intensive echoes at low levels around Owase than over more eastern or western area.

Fig. 23 is the vertical profiles of echo intensity. Since inclined streaks travelled eastward successively, the echo intensities averaged for one hour and for the region of $2 \mathrm{~km}$ in width of $E$ to $W$ centering the radar site are shown in the figure. The increase in echo intensity with decreasing height is remarkable below $3.75 \mathrm{~km}$ before 18.00 and small increase can be seen only below $2 \mathrm{~km}$ after 21.00. Though the peak value in the bright
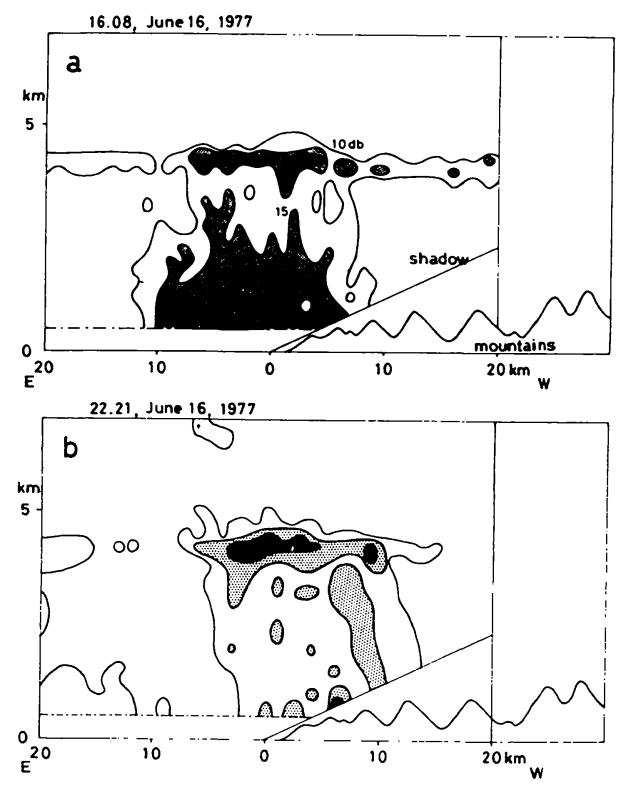

Fig. 22 Vertical cross sections of echo intensity at 16.08 (a) and 22.21 (b) on the 16th of June. Contours are drawn every $5 \mathrm{db}$. band was nearly the same for the periods of 15.25 to 16.00 and 22.00 to 23.00 , the hourly rainfall recorded at Owase station is $11.5 \mathrm{~mm}$ and $3.0 \mathrm{~mm}$ for two periods, respectively. It is clear that the precipitation from middle-level-clouds was modified due to the cloud system which was formed persistently at low levels around Owase. However, it is not clear whether precipitation particles grew by the capture of cloud droplets in low-level clouds or falling raindrops produced in low-level clouds were added merely to them. The latter process implies that the rainfall observed on the ground was the mere sum of rainfall from middle-level clouds and that from lowlevel clouds, and the former does the addition of cloud water, which was not able to be converted into rainwater in low-level clouds themselves, to the above-mentioned sum.

Fig. 6 indicates that an easterly wind was prevalent in the layer below $900 \mathrm{mb}$ level at 9.00 on the $16 \mathrm{th}$, but it was found out only near at the earth surface at 21.00. This fact, together with observational facts described in the previous chapter, seems to verify that the easterly wind is needed in the lower layer in order that a convective cloud system is formed at low levels around Owase and the cloud system causes the precipitation from middle-level clouds to increase at low levels. Some other conditions such as thermal instability will be of course necessary for its formation in addition to easterly winds. These facts obtained by quantitatively observed echo structure would give positive proof of the necessary condition of easterly winds, which has

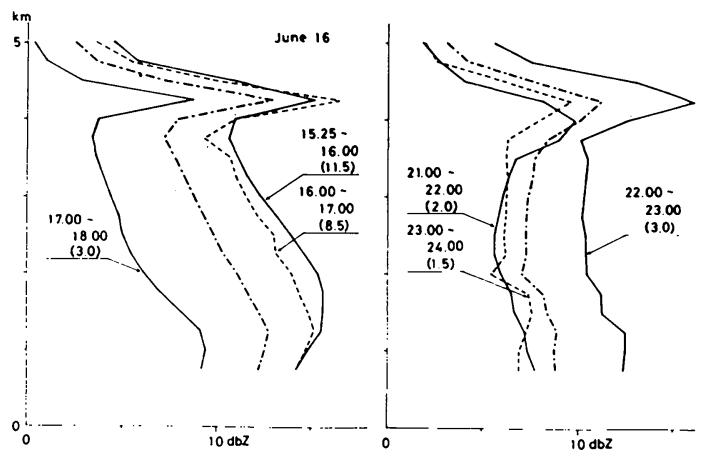

Fig. 23 Vertical profiles of echo intensity which are averaged for one hour and in the region of $2 \mathrm{~km}$ in width of $\mathrm{E}$ to $\mathrm{W}$ centering the radar site. Numerals in parenthesis are hourly rainfall. Chain lines are vertical profiles of echo intensity averaged from 15.25 to 18.00 and 21.00 to 24.00 , respectively. 
been pointed out by many authors.

ii) Intensification of middle-level echoes

We can see in Fig. 22 that the echo intensity of the bright band was also larger above the area around the sea shore than above the eastern or western area. As shown in Fig. 22b and in Fig. 23 , it was not observed after 21.00 that the precipitation from middle-level clouds increases with decreasing height below bright bands remarkably. However, even in the cross section at 22.21, we can find out the intensive echo with ten-odd $\mathrm{km}$ in width of $\mathrm{E}$ to $\mathrm{W}$ at low levels around the sea shore. It seems to consist mainly of the precipitation particles falling from middlelevel clouds.

Fig. 24 shows the time and horizontal variations of the largest echo intensity seen around the level of bright bands. The values of echo intensity averaged for one hour and in the region of $5 \mathrm{~km}$ in width of $\mathrm{E}$ to $\mathrm{W}$ are indicated in the figure. They are clearly larger above the radar station than those above other areas on both sides. It will be expected that if large precipitation particles occupy the lower atmosphere over the wide area, the space variation of echo intensity at middle-levels such as seen in Fig. 24 tends to be realized as a result of the attenuation of radar signals due to particles existing on the way. The influence of the attenuation was estimated by the method of Kodaira (1963) on the assumption that the atmosphere between the ground and the level of $3 \mathrm{~km}$ is filled uniformly with raindrops which will produce the rain of $5 \mathrm{~mm} /$ hour or $10 \mathrm{~mm} /$ hour in intensity. It is shown in the upper part of Fig. 24. The largest value of the attenuation which is expected to occur on one way is shown in the figure, because it is much

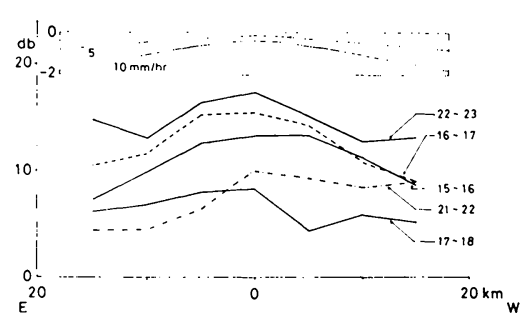

Fig. 24 Time-and horizontal variations of the largest echo intensity, which is averaged for one hour and in the region of $5 \mathrm{~km}$ in width of $\mathrm{E}$ to $\mathrm{W}$, around the level of bright bands. The attenuation of radar signal which is caused on one way due to raindrops corresponding to rainfall intensity of $5 \mathrm{~mm} / \mathrm{hr}$ or $10 \mathrm{~mm} / \mathrm{hr}$ is shown in the upper part of the figure. dependent upon the size distribution of raindrops. The attenuation estimated on both ways in the case of $10 \mathrm{~mm} /$ hour seems to be almost the same as the observed horizontal variation of echo intensity, which is shown in the lower part of Fig. 24. Considering that the rainfall of $10 \mathrm{~mm} /$ hour did not occupy actually the layer between the ground and the level of $3 \mathrm{~km}$ over the wide area and that the estimated value is the largest one expected in the real atmosphere, it might be a reliable fact that the intensive radar echoes were found out at middle-levels over the area around the sea-shore. Probably it will be on account of the attenuation caused by precipitation particles in the lower layer that the peak values were observed almost always above the radar station.

As seen in Fig. 5 westerly winds were prevailing above the level of $800 \mathrm{mb}$ and so the regional difference of echo intensity shown in Fig. 24 appeared in the lee side of mountains of $\mathrm{Kii}$ peninsula. It will be reasonable to interpret that the regional difference seen in the bright band was not as a result of the difference in the formation- and growth-processes of precipitation particles occuring in melting layer, but it reflected the difference in the dynamical features of middlelevel clouds existing above the level of bright band as well as the formation processes of precipitation in them.

The influence of orography on middle-level clouds was pointed out by Browning, Hill and Pardoe (1974). They stated that mountains have an influence on the release of potential instability at middle-levels in the windward side of them. The orographic influence described in the present paper occurred in the lee side of mountains at middle levels. Since the radar beam was scanned only in the vertical plane of $E$ to $W$, it is not clear how widely the regional difference in echo intensity appeared in the direction of $\mathbf{S}$ to $\mathrm{N}$. The reliability and the mechanism of the orographic influence on middle-level clouds has to be studied by more detailed radar observations and others.

\section{2) Rainfalls on the 18th and the 23rd of June}

Fig. 20 indicates that 24 hours rainfall on the $18 \mathrm{th}$ and on the $23 \mathrm{rd}$ were $7 \mathrm{~mm}$ and $57 \mathrm{~mm}$, respectively. On both days middle-level echoes were travelling eastward and rather scattered horizontally. Since their intensity was weak, we will make only qualitative discussions here. A typical example of vertical cross sections observed on the 18th is shown in Fig. 25. Only a streak of precipitation particles is recognized 


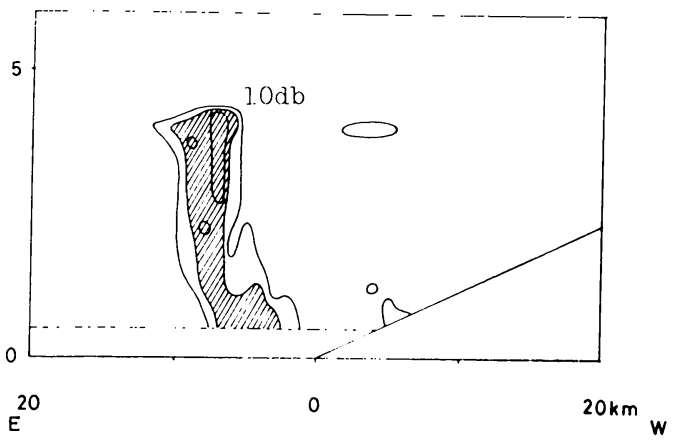

Fig. 25 Vertical cross section of echo intensity at 4.10 on the 18 th of June. Contours are drawn every $5 \mathrm{db}$.

below $0^{\circ} \mathrm{C}$ level as the echo of intensity more than $10 \mathrm{db}$ and the increase in echo intensity with decreasing height is not seen in the streak. On the 18th only this type of echoes were sometimes observed and we did not find out any echo formed at low levels around the sea-shore. It can be said from Fig. 6 that easterly winds were not prevailing at low levels during the rainfall period of 2.00 to 7.00 on the 18 th, since westerly winds were prevalent through the whole layer at 21.00 on the 17th and easterly winds were found out only near the earth surface at 9.00 on the 18 th.

On the 23rd easterly winds were prevalent below the level of $800 \mathrm{mb}$. Low-level convective echoes travelling from the east were observed persistently. However, middle-level echoes were rarely recognized. So far as the rainfall period of 1.00 to 5.00 is concerned, the peak value of hourly rainfall was recorded during the period of 2.00 to 3.00. As seen in Fig. 26 middle-level echoes more than $5 \mathrm{db}$ were detected above the radar site for only a few ten minutes within the period and echoes observed at the level of $1 \mathrm{~km}$ above the site were also more intensive as a whole in the period than those in other periods.

Vertical cross sections shown in Fig. 27 visualized a very interesting time variation of echo structure. Low-level echoes showed a rapid development during the period of 2.20 to 2.34 , though unfortunately we were not able to make an observation during the period duc to some troubles of the radar. It was recognized in the case of June 16 that the intensity of radar echo increased below bright bands with decreasing height. The increase can be interpreted to be partly due to the addition of raindrops formed in low-level clouds to the precipitation particles originated from middle-level clouds and partly due to the growth of the latter particles as a result of the capture of cloud droplets in low-level clouds. It could not be determined which process had a larger contribution to the increase in echo intensity. It will be very difficult to distinguish the latter process, a kind of "seeding", from the former process.

The rapid time change in echo intensity seen in Fig. 27 seems to suggest the occurrence of the effect of seeding of precipitation particles of middle-level clouds on low-level clouds. Middlelevel echoes were travelling from the west, but they were not found out just above the low-level echoes at 2.34 . It will be highly probable that middle-level precipitating clouds which were not able to be detected by the radar existed in front of echoes travelling from the west and small particles were supplied from middle-level clouds onto low-level ones. The verification of the seeding effect of upper clouds on lower ones is an interesting problem to be studied in detail. The detailed analysis of echo structure observed on the 23rd will be described in another paper together with the discussion of the electrical charge of precipitation particles measured on the

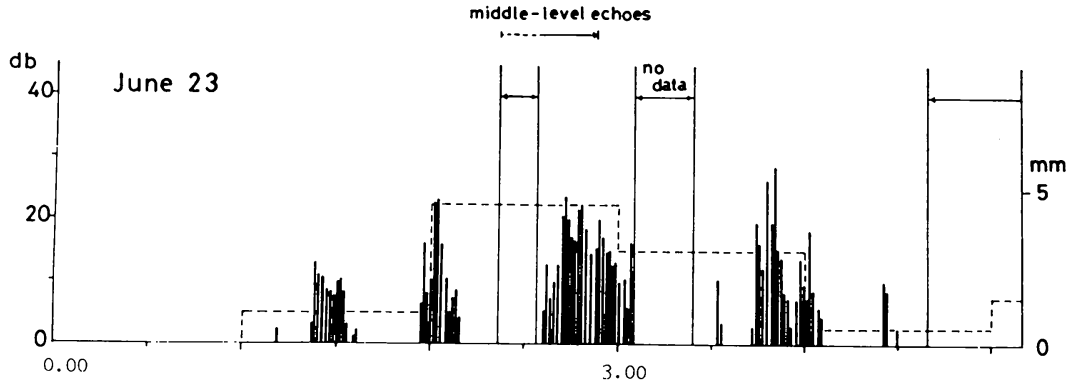

Fig. 26 Time variations of echo intensity at the level of $1 \mathrm{~km}$ above radar site and hourly rainfall (dashed line). A bar is the period during which middle-level echoes more than $5 \mathrm{db}$ were detected. 

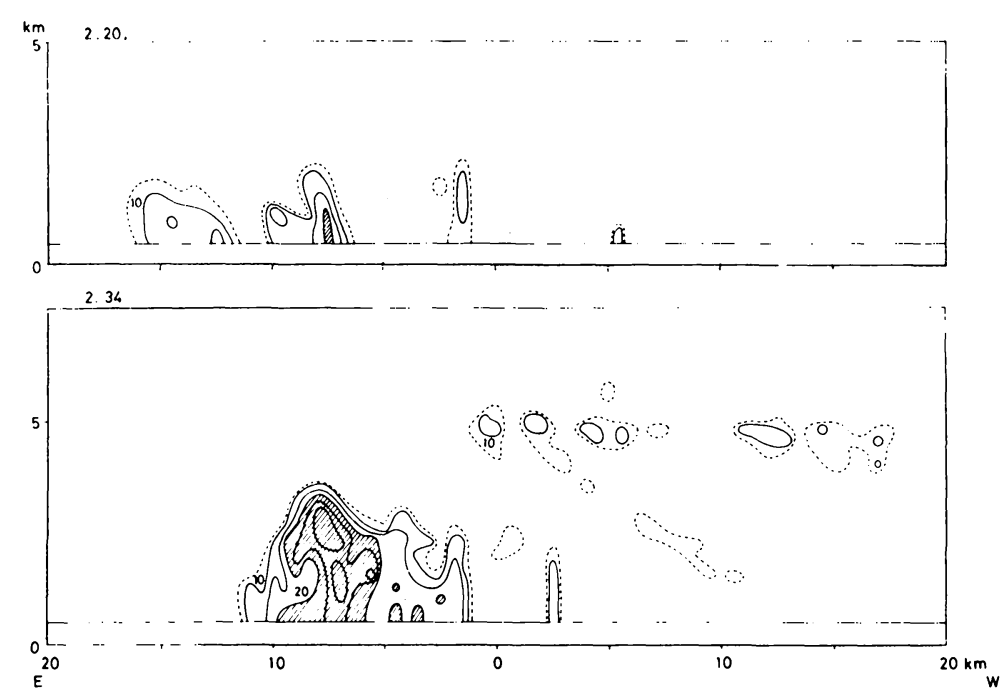

Fig. 27 Vertical cross sections of echo intensity at 2.20 and 2.34 on the $23 \mathrm{rd}$ of June. Contours are drawn every $5 \mathrm{db}$. Dashed lines are contours of $5 \mathrm{db}$.

ground.

\section{Summary}

In order to understand the formation of orographic rain and the orographic enhancement of rainfall, we studied the modification of rainfall system by orographic effects on the basis of the echo structure observed quantitatively by the RHI radar which was set in Owase city located in the southeastern side of $\mathrm{Kii}$ peninsula during the period of June to July in 1977. Several types of rainfalls were observed.

1) When easterly wind was prevalent in the lower layer, a long-lasting precipitating cloud system which was fixed around the sea shore in front of mountains was observed. It was not a layer-type cloud expected from an upcurrent forced due to orographic effect, but a convective one whose top exceeded the level of $4 \mathrm{~km}$ in spite of the mountains of $1 \mathrm{~km}$ in height. The longlasting cloud system, which had the size of about $4 \mathrm{~km}$ in height and about $15 \mathrm{~km}$ in width of $E$ to $\mathrm{W}$, was composed of several small precipitating convective clouds of 3 to $4 \mathrm{~km}$ in width. These convective clouds were formed successively in nearly the same region over the sea and they travelled to west (to the mountain side). Though the individual convective cloud was a so-called short-lived type, the cloud system was maintained for a long time as a result of their successive formation in the same area and their travelling with the same evolution. The horizontal convergence field caused by orographic effect in the windward side of mountains and by a downdraft originated in the previously devcloped cloud would have been important in the successive formation of the new convective cloud.

2) In the case in which rainfall generated in middle-level clouds was found out over the wide area of Kii peninsula, the remarkable increase in echo intensity with decreasing height was observed below bright band when easterly wind was prevalent at low-levels, but it was not detected when easterly wind was limited only near the earth surface or westerly one was prevalent. In the former situation, low-level clouds of about $20 \mathrm{~km}$ in width of $\mathrm{E}$ to $\mathrm{W}$ and $3 \mathrm{~km}$ or more in height were formed around the sea shore. Hourly rainfall recorded at Owase station was $11.5 \mathrm{~mm}$ in the former situation and $3.0 \mathrm{~mm}$ in the latter, though a large difference was not found out in the echo intensity of bright band. This fact indicates that precipitation from middle-level clouds increased considerably in low-level clouds formed around the sea shore line when easterly wind was prevalent at low levels.

3) The echo intensity of bright band also showed a tendency to be larger around the sea shore, even if the attenuation of radar beam due to water drops was taken into account. This suggests that middle-level clouds might have been influenced in the lee side of mountains in the 
situation of westerly wind.

4) Low-level echocs showed a rapid development in the existence of travelling middle-level echoes. This might be interpreted to be the rapid growth of water drops in low level clouds due to the supply of precipitation particles originated from middle-level clouds-in other words, "seeding effect"-, not the mere addition of raindrops formed in low-level clouds to particles falling from middle-level clouds, though both processes would have occurred in the case mentioned in 2).

5) When long-lasting convective echoes formed over the sea travelled to the land, they were intensified and modified in landing. They decayed rapidly after landing. After their dissipation lowlevel cloud system described in 1) was formed in the windward side of mountains. It was not a layer-type cloud, but it was composed of convective oncs. The system itself showed the efficient generation of precipitation, and it caused the enhancement of precipitation originated from middle-level clouds.

\section{Acknowledgements}

The authors wish to express their hearty thanks to staff members of Owase Meteorological Station and Owase City Office for offering conveniences to their observations. The authors are also indebted to Nagoya Meteorological Observatory for the supply of radar photographs and to Mr. S. Murabayashi, Mr. T. Ohtani and Mr. Y. Fujiyoshi of Nagoya University for assisting their observations. This study was supported by a Fund for Scientific Research from the Ministry of Education.

\section{References}

Browning, K. A., F. F. Hill and C. W. Pardoe, 1974: Structure and mechanism of precipitation and the effects of orography in a wintertime warm sector. Quart. J. Roy. Meteor. Soc., 100, 309-330.

Colton, D. E., 1976: Numerical simulation of the orographically induced precipitation distribution for use in hydrologic analysis. J. Appl. Meteor., 15, 1241-1251.

Fujiwara, M., J. Aoyagi, J. Shiino and T. Yanase, 1974: On the cloud structure related to heavy rainfall as revealed by radar. Papers in Meteor. and Geophys., 25, 24-50.

Gocho, Y., 1978: Numerical experiment of orographic heavy rainfail due to a stratiform cloud. $J$. Meteor. Soc. Japan, 56, 405-423.

Sakakibara, H. and T. Takeda, 1973: Modification of Typhoon 7002 rainfall by orographic effect. J. Meteor. Soc. Japan, 51, 155-167.

Sarker, R. P., 1966: A dynamical model of orographic rainfall. Mon. Wea. Rev., 94, 555-572.

Sawyer, J. S., 1956: The physical and dynamical problems of orographic rain. Weather, 11, 375381.

Staff members, Division of Meteorology, Tokyo University, 1969: Precipitation bands of Typhoon Vera in 1959. Part 1. Meteor. Soc. Japan, 47, 298-309.

, 1970: Precipitation bands of Typhoon Vera in 1959. Part 2. J. Meteor. Soc. Japan, 48, 103-117.

Takeda, T., N. Moriyama and Y. Iwasaka, 1976: A case study of heavy rain in Owase area. J. Meteor. Soc. Japan, 54, 32-41.

Tatehira, R., 1976: Orographic rainfall computation including cloud-precipitation interaction. Tenki, 23, 95-100, in Japanese.

Yanagisawa, Z., J. Aoyagi and N. Kamibayashi, 1974: Radar analysis on the precipitation around Owase. Papers in Meteor. and Geophys., 25, $51-80$.

\title{
地形の効果により変質した降水系のレーダー観測
}

\author{
武 田喬 男・高 瀬 邦 夫* \\ 名古屋大学 水圈科学研究所
}

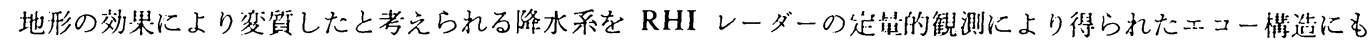

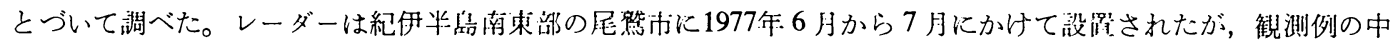

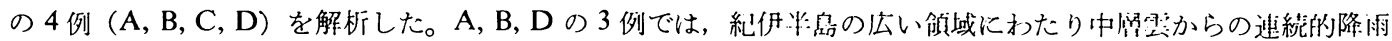
が起って挆り，C例では対流件降雨が注岸沿いの限られた領域にの及起っていた。

C 例では東よりの風がト居で令越していたが，高さ $4 \mathrm{~km}$, 来西の幅 $15 \mathrm{~km}$ 程度の対流件:の降水具系が海岸付 


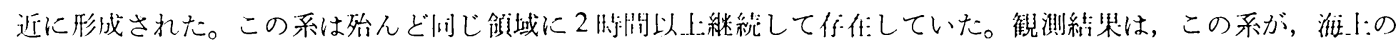

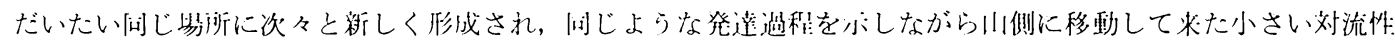

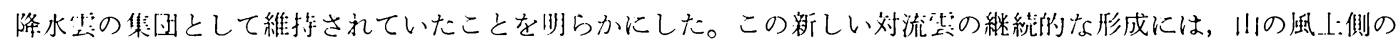

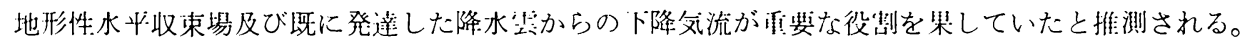

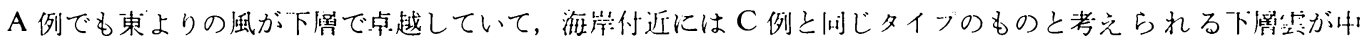

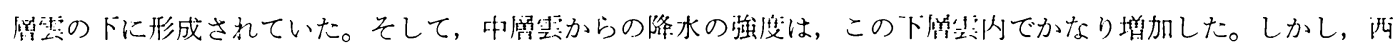

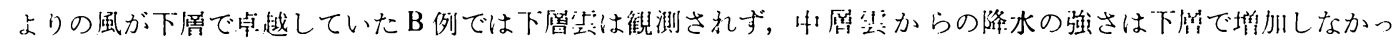

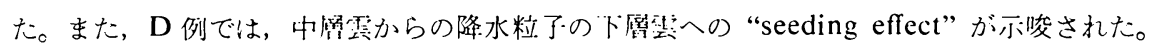

